\title{
Unzipping Lemuria from its Himalaya suture to understand mammalian origins
}

\author{
Maarten J de Wit $^{1^{*}}$ and Judith Masters ${ }^{2}$ \\ ${ }^{1}$ AEON - Africa Earth Observatory Network and Department of Geological Sciences, University of Cape Town, Rondebosch 7700, SOUTH AFRICA \\ 2 Department of Zoology, University of Fort Hare, Private Bag X1314, Alice 5700, SOUTH AFRICA \\ * For correspondence, email: maarten.dewit@uct.ac.za
}

Information relating to the suturing history between India and Asia is crucial to understanding the historical biogeography of living mammals. It is particularly relevant to understanding the origins of Madagascar's mammal fauna that contributes to the island's standing as one of the worlds' biodiversity hotspots. Evolutionary biologists are strongly divided as to the timing and place of the origins of extant mammalian orders. Most palaeontologists stand by the opinion that living mammal orders arose after the $\mathrm{K} / \mathrm{T}$ boundary $(66 \mathrm{Ma})$ in the northern hemisphere, while molecular phylogeneticists push these divergences back into the Cretaceous $(\geq 100 \mathrm{Ma})$ and favour a southern hemisphere origin. Recent discovery of an ungulate fossil at about $65 \mathrm{Ma}$ in peninsular India supports the molecular argument. Within the circa $40 \mathrm{Ma}$ period that separates the two estimates, the global palaeobiogeography of the Indian Ocean changed dramatically as continents moved and oceans evolved rapidly during the final break-up of Gondwana and the suturing between India and Asia. A detailed understanding of the movement and suturing history of India will allow biologists to formulate more robust scenarios of early mammalian dispersal, and perhaps identify, finally, the places of origin of major mammal clades.

The precise extent of palaeo-continental lithosphere north of India that vanished following the sub-continent's collision with
Asia is poorly quantified. Argand, in 1922, assumed it stretched all the way from northern India, then in the southern hemisphere as part of Gondwana, to Asia. He called this landmass Lemuria and predicted that during continental drift away from Gondwana, much of Lemuria was thrust beneath Asia. We know this to be incorrect in detail today, but the concept is still with us. Yet facts about the chemical and physical composition of this continental shelf to the north of paleo-India are few. There is also a lack of consensus on the precise timing (and possible along-strike diachronous events) of docking and final suturing between Lemuria and Asia. The fragmentation history of Gondwana and the evolution of the Indian Ocean are now well-enough understood to re-evaluate evidence for transient land bridges, given the unlikelihood of crosswater dispersals of early mammals between different fragments of Gondwana, and especially between Africa, Madagascar and India. Resolution of the uncertainties associated with India's accretion to Asia by geologists and geophysicists will enable biologists to unravel one of the great long-standing debates in natural history that dates back to the heydays of AR Wallace and C Darwin, i.e. the colonization of Madagascar. In this presentation we outline the major controversies relating to this problem, and show how a detailed analysis of the events that occurred along the length of the suture will contribute to resolving this debate. 